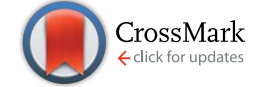

Cite this: RSC Adv., 2017, 7, 4830

Received 14th November 2016 Accepted 2nd January 2017

DOI: 10.1039/c6ra26770j

www.rsc.org/advances

\section{One-step fabrication and characterization of a poly(vinyl alcohol)/silver hybrid nanofiber mat by electrospinning for multifunctional applications $\dagger$}

\author{
Chun-Gang Yuan,* Shiwei Guo, Jian Song, Can Huo, Yukai Li, Bing Gui \\ and Xianmei Zhang
}

A poly(vinyl alcohol)/silver (Ag-PVA) nanofiber mat was synthesized by electrospinning. The fabricated composite was characterized by scanning electron microscopy (SEM), powder X-ray diffraction (XRD), FTIR spectroscopy, and energy dispersive spectroscopy (EDS). The obtained mat showed good capacity for the removal of mercury ions from water and antibacterial activity. The possible interaction mechanisms between PVA, silver nanoparticles and mercury were investigated by X-ray photoelectron spectroscopy (XPS). The batch adsorption experiment showed that the composite had good performance for removing mercury ions with good stability to $\mathrm{pH}$ and temperature. The adsorption capacity of the composite could be easily regenerated via thermal treatment. The influences of parameters including coexisting ions and the initial concentration of mercury were investigated. The adsorption process followed pseudo-second-order kinetics and the Langmuir isotherm model. The thermodynamic parameters (enthalpy $(\Delta H)$ ), entropy $(\Delta S)$ and free energy $(\Delta G)$ ) of $\mathrm{Hg}^{2+}$ sorption were evaluated. The antibacterial tests revealed that the membrane had excellent antibacterial properties. The composite mat has potential for both mercury pollution control and antibacterial applications for water treatment.

\section{Introduction}

Long term exposure to mercury can lead to psychological changes, spontaneous abortion and congenital malformation., ${ }^{\mathbf{1 , 2}}$ During the biogeocycling process of mercury, inorganic mercury can be transformed into methylated compounds and cause serious damage to brain and central nervous systems. ${ }^{3-6}$ Trace mercury in natural water can be elevated up to very high concentrations in seafood along with aquatic food chains through biomagnification and bioconcentration..$^{7-10}$ Therefore, it is very urgent and important to develop effective technologies to remove trace or ultra trace mercury ions from water bodies.11,12

There has been much research in this field and many technologies have been developed to remove mercury from water. ${ }^{13-22}$ The techniques include adsorption, ion exchange, chemical precipitation, membrane separation, filtration, chemical oxidation or reduction. Among these techniques, adsorption is regarded as the most promising method due to its easy operation and high efficiency. ${ }^{13-17}$ In consequence, various adsorbents have been investigated including active carbon based materials, metal and metal oxides, natural minerals and

School of Environmental Science \& Engineering, North China Electric Power University, Baoding 071000, China. E-mail: chungangyuan@hotmail.com; Fax: +86312-7525512; Tel: +86-312-7525512

$\dagger$ Electronic supplementary information (ESI) available. See DOI: $10.1039 / \mathrm{c} 6 \mathrm{ra} 26770 \mathrm{j}$ others. $^{23-25}$ However, these granular or powdered adsorbents have the drawbacks of difficulty for collection and separation from bulk water, which makes the used adsorbents to readily cause secondary pollution. The above problems can be solved by application of membranes or mats instead of powder adsorbents. Recently, some membranes have been applied to remove heavy metals from water. ${ }^{26-29}$ These studies demonstrate that fiber membranes or mats exhibit great advantages of easy separation and collection after use over powdered adsorbents. Nanofibers with highly porous property and large surface area are regarded as a promising candidate adsorbent for aqueous mercury elimination.

Electrospinning technology appeared as a promising method to prepare nanofibers and attracted great attentions several years ago. ${ }^{30}$ Compared with the conventional technologies, electrospinning shows many advantages such as easy operation, effectiveness and other excellent properties. Many kinds of polymer composites were synthesized and applied in various fields. ${ }^{31}$ Due to the characters of low diameter, high surface area to volume ratio and porous structures, electrospinning membrane/mat can act as an effective adsorbent for pollution control.

To modify the obtained membrane/mat with functional groups or metal/metal oxide nanoparticles is a feasible route to enhance its adsorption capacity and selectivity. ${ }^{32}$ Teng et al. ${ }^{33}$ prepared (PVP) $/ \mathrm{SiO}_{2}$ composite nanofiber membranes functionalized with thioether groups and used it for mercury 
removal. Wang et al. ${ }^{26}$ synthesized uracil-functionalized polymer based fiber membrane which was able to distinguish and selectively remove mercury ions $\left(\mathrm{Hg}^{2+}\right)$ from other metal ions in aqueous solution. Huang et $a .^{34}$ developed thymine-grafted PVA-PEI nanofibers for selective removal of mercury ions $\left(\mathrm{Hg}^{2+}\right)$ with high efficiency. On the other hand, previous studies indicate that the elemental silver $\left(\mathrm{Ag}^{\mathrm{O}}\right)$, especially silver nanoparticles, show good amalgamation effect and high affinity to mercury. These properties have been applied to the detection mercury ions ${ }^{35,36}$ and the removal of elemental mercury. ${ }^{37}$ These studies also inspired us to try a new application of silver nanoparticles for the removal of mercury from water. ${ }^{38}$ Moreover, the antibiotic property of silver nanoparticles has also been proved and widely applied. ${ }^{39}$ The disinfection property can also solve the bio-fouling problems caused by biota when the membrane or mat is used in water solution for a long time. ${ }^{40}$ Therefore, to decorate the nanofibers with silver nanoparticles can not only significantly promote the mercury removal capability but also endow the composite with antibacterial properties. The hybrid electrospinning nanofiber mat of Ag-PVA can potentially be used as a multifunctional adsorbent for water treatment.

Some fibers had been successfully synthesized and applied in many areas including heavy metal pollution treatment. ${ }^{41,42}$ However, to the best of our knowledge, there is no research on the application of Ag-PVA composite mat for aqueous mercury removal. Furthermore, the conventional synthesis methods of nanofibers modified with AgNPs are relatively complicated in most reports. The typical processes normally include individual chemical and physical steps to reduce silver ions to elemental form, which makes the process time and energy-consuming. ${ }^{43,44}$ It was also reported that some polymers, such as PVA and PVP, were able to reduce silver ions into elemental silver directly without any additional reagents. ${ }^{39,45}$ This feature of PVA makes it possible to develop a novel, and environmental friendly fabrication method in one step. It can be expected that the polymers can be used as both precursor solvent of nanofibers and reductants for silver ions during modification process by electrospinning.

The aims of this study are (1) to develop a handy, green and rapid route to prepare Ag-PVA nanofiber composite using electrospinning technology in one step and (2) to evaluate its adsorption behaviors for mercury ions and antibacterial properties. Batch adsorption experiments were conducted to investigate the adsorption performance. The effects of experimental parameters including solution $\mathrm{pH}$ value, temperature, coexisting ions on the adsorption efficiency were investigated. The dynamic and thermal mechanisms of the adsorption process were studied and discussed as well. In addition, the antibacterial property of the mat was also tested.

\section{Experimental}

\subsection{Material}

Poly(vinyl alcohol) (PVA, 1788) was provided by Shanghai Jinbaidi company in China. Standard mercury solution (GSB-041729-2004) was obtained from the Chinese Research Center for Analysis and Testing of Nonferrous Metals and Electronic Materials. Silver nitrate $\left(\mathrm{AgNO}_{3}, 99.8 \%\right)$ was obtained from Tianjin Tiangan Chemical Company, China. All the other regents including nitric acid $\left(\mathrm{HNO}_{3}\right)$, hydrochloric acid $(\mathrm{HCl})$ and the metal salts used in this study were of analytical grade and were purchased from commercial sources in China.

\subsection{Synthesis of composite nanofiber mat using electrospinning}

A series of Ag modified PVA fiber mats with different contents of silver loaded were synthesized via electrospinning. The nanofibers were crosslinked by heat treatment at $150{ }^{\circ} \mathrm{C}$ to make the obtained composite insoluble in water.

The electrospun precursor solution was prepared by the following process. Firstly, $10 \%(\mathrm{~m} / \mathrm{v})$ PVA solution was prepared by dissolving $1.0 \mathrm{~g}$ PVA particles in $10 \mathrm{~mL}$ distilled water with a vigorous agitation at $70{ }^{\circ} \mathrm{C}$ in a water bath for 2.0 hours to obtain a homogeneous transparent solution. Secondly, an appropriate amount of $\mathrm{AgNO}_{3}$ was added to $10 \%$ PVA solution and magnetically agitated at room temperature for another 2.0 hours until $\mathrm{AgNO}_{3}$ was completely dissolved. The color of the mixture gradually turned from transparent to grey brown. The mat was then prepared with the obtained solution by an electrospinning instrument (Beijing Yongkangleye Company, China). The precursor solution for spinning was placed in an injector. The electrospinning parameters including voltages, distance between needle and collector, and flow rate were optimized and

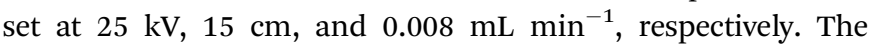
electrospinning was performed in air at room temperature.

The as-prepared composite mat was treated in an oven with temperature rising from room temperature to $150{ }^{\circ} \mathrm{C}$ and maintained for 2.0 hours. The color of the membrane changed to deep yellow. After cooling down to room temperature the membrane was dissected into smaller pieces for use in the following experiments.

\subsection{Characterization}

The morphology of the prepared composite fiber mat was characterized and the elemental components of the mat were analyzed by EDS using a field emission scanning electron microscope (FE-SEM, Hitachi S4800) at an acceleration voltage of $20 \mathrm{kV}$.

X-ray powder diffraction patterns (XRD) were recorded in a $2 \theta$ range of $25-80^{\circ}$ on an equipment (Ultima IV) provided by Rigaku Co. to measure the presence of silver nanoparticles.

FT-IR spectra of prepared mat before and after thermal treatment were recorded using a FT-IR spectrophotometer (Avatar 370, Thermal Nicolet Co.) in the region of 4000-400 $\mathrm{cm}^{-1}$ for the identification of functional groups on the mat.

X-ray photoelectron spectroscopy (XPS) through the facility of Escalab 250X (Thermal Scientific Co.) was utilized to explore the existence state of the main elements in the composite.

\subsection{Adsorption experiment}

The adsorption performance of the as-prepared mat was investigated by batch adsorption experiment. During the 
experiment, $40 \mathrm{mg}$ of mat was added into $40 \mathrm{~mL}$ of $\mathrm{Hg}^{2+}$ solution. The solution was shaken on a thermostatic shaker at designed temperature until the equilibrium reached. $\mathrm{Hg}^{2+}$ solution used for adsorption was prepared by diluting the standard mercury solution $\left(1000 \mu \mathrm{g} \mathrm{mL}^{-1}\right)$ to $20 \mathrm{ng} \mathrm{mL}{ }^{-1}$ with deionized water. The ratio of membrane to mercury solution was fixed at $1: 1000$ (40 mg of membrane to $40 \mathrm{~mL}$ of solution).

The mercury concentration in the final aqueous solution was measured using a cold vapor atomic fluorescence mercury analyzer (QM 201, Suzhou Qing'an Company). The adsorption amount of mercury ion was calculated by the eqn (1) and the removal efficiency was calculated using the eqn (2).

$$
\begin{gathered}
q=\left[V\left(C_{0}-C_{t}\right)\right] / m \\
r=\left[\left(C_{0}-C_{t}\right) / C_{0}\right] \times 100 \%
\end{gathered}
$$

$q$ is the amount of mercury adsorbed at equilibrium $\left(\mathrm{mg} \mathrm{g}^{-1}\right)$, $C_{0}$ is the initial concentration of mercury ion in solution $(\mathrm{mg}$ $\left.\mathrm{L}^{-1}\right), C_{t}$ is the concentration of metals in solution at equilibrium $\left(\mathrm{mg} \mathrm{L}^{-1}\right), m$ is the mass of adsorbent used $(\mathrm{g})$, and $V$ is the volume of solution (L).

\subsection{Antibacterial test}

The antibacterial test was carried out using the zone inhibition test against Escherichia coli and Staphylococcus aureus. All the bacterial suspensions were prepared by growing a single colony overnight at $37^{\circ} \mathrm{C}$ in a nutrient broth and the agar plates were freshly prepared before the antibacterial tests. Pure PVA mat (negative control) and PVA mat modified with 10\%, 20\%, and $40 \%$ silver content (labeled according to the mass ratio of $\mathrm{AgNO}_{3}$ to the membrane) were used and cut into circular shape with $10 \mathrm{~mm}$ diameters. During the experiment, the circular membranes were directly placed on the inoculated agar plates and the gentamicin was also used for the positive control. Then the samples and inoculated agar plates were incubated at $37^{\circ} \mathrm{C}$ for $24 \mathrm{~h}$. After the cultivation the inhibition zone area was measured to evaluate the antibacterial ability.

\subsection{Determination of silver}

2.6.1 Quantification of the silver contents in the mats. The modified PVA fiber mats with different contents of silver were digested by a microwave-assisted digestion system (CEM Mars 5, Xpress, Matthews, NC). Briefly, $4 \mathrm{~mL}$ of the concentrated $\mathrm{HNO}_{3}$ and $1 \mathrm{~mL}$ of the concentrated $\mathrm{H}_{2} \mathrm{O}_{2}$ were added into a microwave digestion tube with $10 \mathrm{mg}$ of the obtained mat. Then the mixture was digested at $120{ }^{\circ} \mathrm{C}(800 \mathrm{~W})$ for $10 \mathrm{~min}$, followed by $180{ }^{\circ} \mathrm{C}(1600 \mathrm{~W})$ for $30 \mathrm{~min}$. After digestion, the samples were diluted and measured by ICP-MS (Agilent 7500ce).

2.6.2 Silver leaching and mass loss measurements. $40 \mathrm{mg}$ of mats with different loaded amounts of $\mathrm{Ag}$ were added into 40 $\mathrm{mL}$ of deionized water, and incubated at $30^{\circ} \mathrm{C}$ using a thermostatic bath. Then $1 \mathrm{~mL}$ of water was taken at the specific intervals, and then digested with $3 \mathrm{~mL}$ of concentrated $\mathrm{HNO}_{3}$ (Merck, Darmstadt/Germany). The samples were diluted with deionized water and the concentration of silver was determined by ICP-MS.

The used mat was heated at $110{ }^{\circ} \mathrm{C}$ for $3 \mathrm{~h}$ and the mass was measured by a analytical balance. The mass loss was calculated by comparing the mass before and after use.

\section{Results and discussion}

\subsection{Characterization}

The photo images of the prepared mats were shown in Fig. S1 $\left(\mathrm{ESI}^{\dagger}\right)$. It can be clearly seen that the color of the pristine mat (image a) turned into dark yellow from ivory color after thermal treatment (image b), which indicated that the further formation of silver nanoparticles during the thermal process.

The micro morphology and structure of the prepared mats were characterized by scanning electron microscope (SEM) and shown in Fig. 1. The as-prepared mat was crossed web with the diameters of separate poly fibers in the range of 200-500 nm (449 $\mathrm{nm}$ in average) (Fig. 1a). The fibers kept good morphology of round fibers after being cross linked by thermal treatment. Silver nanoparticles were dispersed on the surface of fibers (Fig. 1b). The structure of mat (shape and diameter) was little changed after utilization for mercury removal in solution as shown in Fig. 1c.

To further identify the elemental composition of the whole fiber mat and the microspheres on the fiber, EDS was carried out at different regions of the fibers. The EDS spectra and the element composition were shown in Fig. S2 and Table S1, $\dagger$ respectively. It can be observed that both the large region (Fig. S2a, $\uparrow$ marked with green line) and the microsphere (Fig. S2b, $\uparrow$ marked with red mark) are composed of the same elements (C, O, and $\mathrm{Ag}$ ) with similar contents.

To confirm the presence of silver nanoparticles, XRD was employed and the patterns were depicted in Fig. 2. The diffraction peak at $(2 \theta) 37.8^{\circ}, 43.96^{\circ}, 64.34^{\circ}$, and $77.48^{\circ}$ corresponds to the plane (111), (200), (220) and (311) of the face center cube structure of silver, respectively. The weak peaks indicate the crystallization is not perfect. However, the result can also confidently prove the presence of silver nanoparticles. The result is consistent with that from EDS analysis.

In order to determine the changes of the function groups on the composite before and after heat treatment, the FT-IR was performed and the spectra were shown in Fig. S3. $\uparrow$ Several peaks were found at $3344(3306) \mathrm{cm}^{-1}, 2915 \mathrm{~cm}^{-1}, 1715 \mathrm{~cm}^{-1}, 1373$ $\mathrm{cm}^{-1}$, and $1244 \mathrm{~cm}^{-1}$ in both the treated and the untreated mats. The strong peaks at $3344(3306) \mathrm{cm}^{-1}$ and $1715 \mathrm{~cm}^{-1}$ can be assigned to $\mathrm{O}-\mathrm{H}$. The peak at $2915 \mathrm{~cm}^{-1}$ is contributed by C$\mathrm{H}$. The peaks at $1373 \mathrm{~cm}^{-1}$ and $1244 \mathrm{~cm}^{-1}$ can be ascribed to $\mathrm{C}-\mathrm{H}$ and $\mathrm{C}-\mathrm{O}$, respectively. The peaks are the characteristic FTIR peaks of PVA. All the initial peaks were reserved and no new peaks appeared after thermal treatment, which indicated that the types of functional groups were little changed. However, the peak at $3306 \mathrm{~cm}^{-1}$ corresponding to hydroxyl functional group shifted to the higher wave number $3344 \mathrm{~cm}^{-1}$ verifying the occurrence of cross link between hydroxyls on the PVA or the interaction between silver and hydroxyls during the thermal treatment. ${ }^{46}$ The strong peak of $\mathrm{O}-\mathrm{H}$ at $3344 \mathrm{~cm}^{-1}$ 

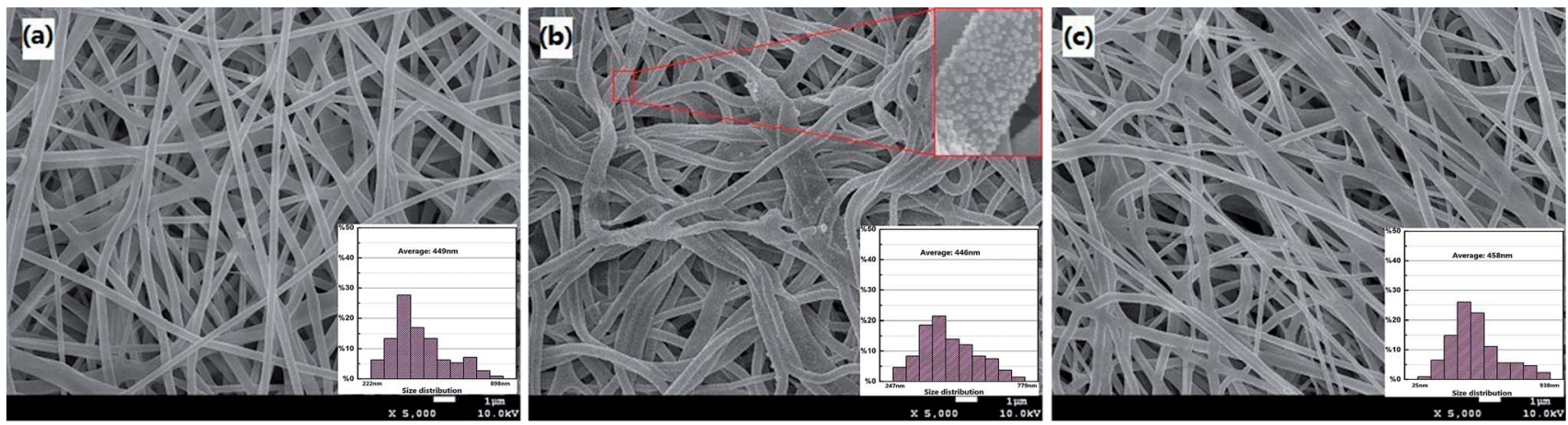

Fig. 1 SEM images of fabrication mat before and after utilizations ((a) initial mat before thermal treatment; (b) mat after thermal treatment; (c) used mat).

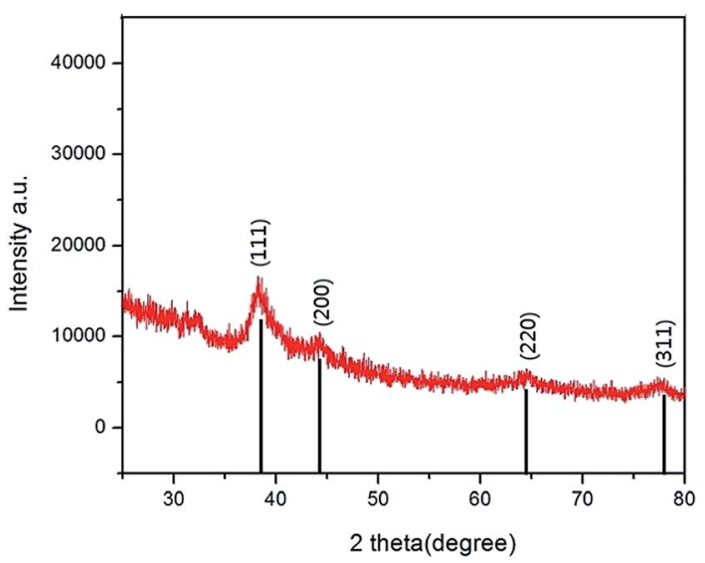

Fig. 2 XRD spectra of the composite mat.

demonstrates that a large number of hydroxyl groups are present on the surface of mat, which can play a very key role during the adsorption process. ${ }^{20}$

The XPS spectra of the mat were shown in Fig. 3. The element ratio obtained from the measurement was shown in Table S2. $\dagger$ As shown in Fig. 3a, the O1s spectrum was divided into five main peaks. Among these peaks, the peak at $531.5 \mathrm{eV}$ is assigned to hydroxyl bonded to metal, perhaps to silver or mercury, and the binding energy at $532.4 \mathrm{eV}$ corresponds to the water adsorbed on the mat. ${ }^{47}$ The peak appeared at $531.8 \mathrm{eV}$ is mainly attributed to chemisorbed oxygen. ${ }^{48}$ The results suggest that the oxygen in the mat plays roles during the mercury adsorption process. As for the Ag3d spectrum in Fig. 3b, one of the two main peaks at $367.6 \mathrm{eV}$ correspond to silver oxide, which can also be explained by O1s at $531.5 \mathrm{eV}$. The main peak of $\mathrm{Hg} 4 \mathrm{f}$ at $101.3 \mathrm{eV}$ can be due to polymer function groups ${\mathrm{or} \mathrm{Hg}^{+}}^{+}$ formed on $\mathrm{Ag}$ nanoparticles suggesting the important role of silver nanoparticles during the mercury removal process. ${ }^{49}$

Accordingly, the mechanism of mercury adsorption on the Ag-PVA composite can be demonstrated in two processes: (1) mercury ion reduction and amalgamation formation, and (2) mercury ion complexation with hydroxyl groups. The first process may play the leading role, which can be supported by the successful recovery of mercury using heat treatment. The second one can promote the whole removal process which can be supported by the adsorption performance of the virgin PVA mat. The possible mechanism of whole adsorption process is similar with the previous reports. ${ }^{38}$

The standard reduction potential of silver $\left(E^{0}\right)$ is $0.80 \mathrm{~V}\left(\mathrm{Ag}^{+}+\right.$ $\left.\mathrm{e}^{-} \rightarrow \mathrm{Ag}^{0}\right)$, which is comparable to that of mercury $\left(\mathrm{Hg}^{2+}+2 \mathrm{e}^{-}\right.$ $\left.\rightarrow \mathrm{Hg}, E^{0}=0.85 \mathrm{~V}\right) .{ }^{26}$ Normally, it is difficult for bulk silver to reduce $\mathrm{Hg}^{2+}$ to elementary mercury $(\mathrm{Hg})$. However, it was reported that the reduction potential of silver would highly decrease with the size decreasing, especially when the size of silver was on nanometer scales. The surface chemistry of silver nanoparticles can be largely changed compared with the bulk material. The reactivity of silver nanoparticles can be greatly enhanced and able to reduce $\mathrm{Hg}^{2+}$ to elementary mercury with partial oxidation of silver. ${ }^{38}$ In this study, the reduced mercury can probably form amalgamation with silver.

In addition, it can be seen from Table S2 $\uparrow$ that the concentration measured from XPS was similar with the results of EDS. It should be noted that both the two methods were semiquantitative and the measurement region and depth of these two methods were different. That is to say, some small differences of results from the two characterization methods should be reasonable. Therefore, it can be concluded that the characterization results of two methods were in consist with each other.

\subsection{Mercury removal performance}

3.2.1 Effect of silver loading amount. To understand the effect of silver loading amount of the composite on mercury removal, the adsorption performances of the mats with different silver loading amounts were carried out. Four precursor solutions with different ratios of $\mathrm{AgNO}_{3}$ to PVA (mg: mL) $(0: 1,0.05: 1$, $0.1: 1$, and $0.2: 1$ ) were named as $0 \% \mathrm{Ag}, 5 \% \mathrm{Ag}, 10 \% \mathrm{Ag}$, and $20 \% \mathrm{Ag}$, respectively. The true amounts of silver in the mats $(0 \%$ $\mathrm{Ag}, 5 \% \mathrm{Ag}, 10 \% \mathrm{Ag}$, and $20 \% \mathrm{Ag}$ ) were quantified by ICP-MS at $0 \mathrm{mg} \mathrm{g}^{-1}$ (below the detection limit of ICP-MS), $27.4 \pm 1.8 \mathrm{mg} \mathrm{g}^{-1}$, $56.5 \pm 1.2 \mathrm{mg} \mathrm{g}^{-1}$ and $96.1 \pm 1.4 \mathrm{mg} \mathrm{g}^{-1}$.

Fig. 4 showed mercury removal performance of four mats with different silver contents. The results demonstrated that the adsorption performances of the mat were obviously promoted by silver modification. PVA mat without modification also showed certain capacity for mercury removal. The adsorption 

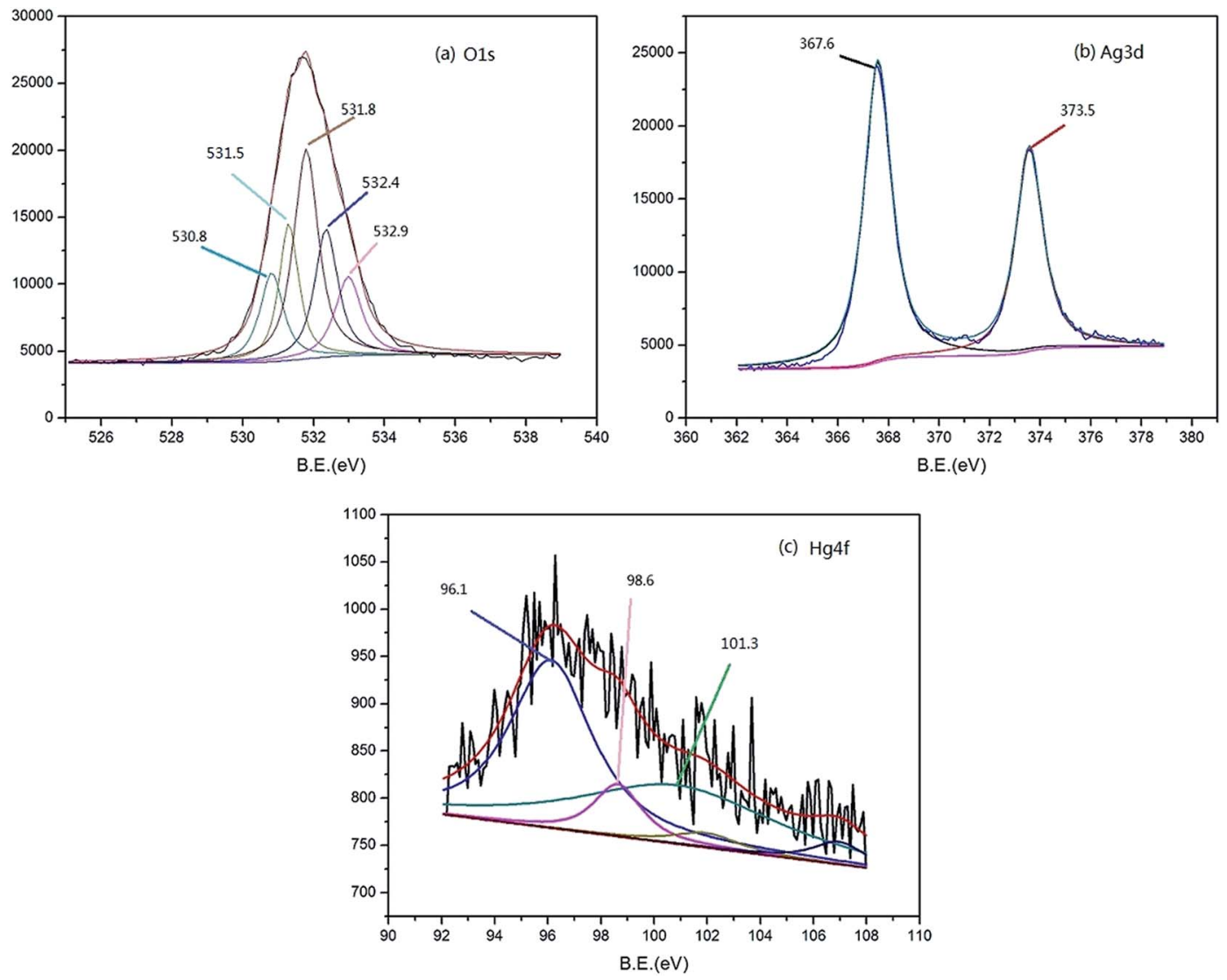

Fig. 3 XPS spectra of the main elements in the composite mat.

was probably caused by the hydroxyl groups on the surface of the mat. The mercury removal efficiency of PVA mat increased from about $70 \%$ to $\sim 100 \%$ by silver modification. The significant enhancement of removal efficiency indicated that silver nanoparticles on the surface of fibers played a key role during adsorption process. However, the removal efficiency increased slightly as the silver loading amount increased from 0.05 to 0.2 .

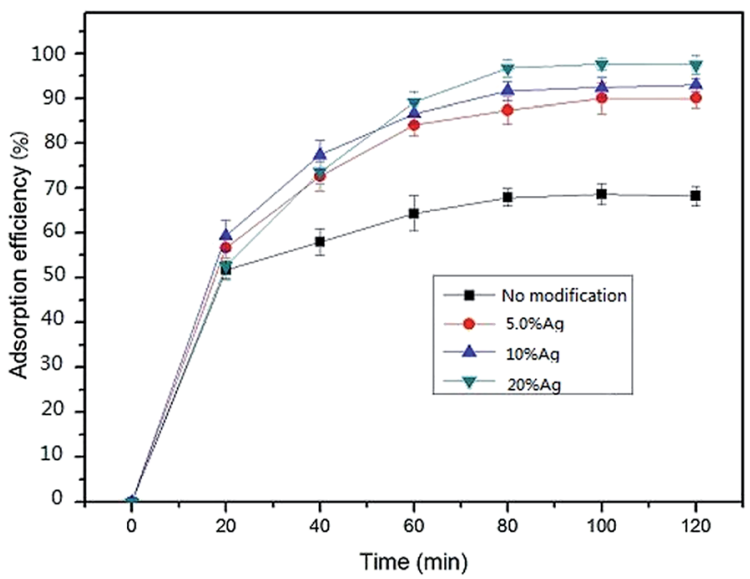

Fig. 4 Removal performance of mats with various silver loading amounts $\left(C_{0}=20 \mathrm{ng} \mathrm{mL}^{-1}, \mathrm{~V}=50 \mathrm{~mL}, m=50 \mathrm{mg}, 25^{\circ} \mathrm{C}\right)$.
The removal efficiency increased sharply from 0 to $\sim 60 \%$ within 20 minutes and then slowly increased to adsorption equilibrium platform during the following 60 minutes. The performance can be interpreted by that a large number of vacant adsorption sites were available during the initial stage, and then the adsorption sites decreased with time till equilibrium reached. Definitely, silver modification shortened the equilibrium time of the mat for mercury adsorption.

3.2.2 Effect of pH. In order to investigate the effect of solution $\mathrm{pH}$ on mercury removal efficiencies batch adsorption experiments were conducted at $\mathrm{pH}$ ranging from 3.0 to 12.0 (Fig. 5). The removal efficiency of unmodified PVA mat was lower than $40 \%$ in the $\mathrm{pH}$ range of 3.0 to 4.0 , and increased up to $70 \%$ with the increase of $\mathrm{pH}$ to 7.0 . Further increase of $\mathrm{pH}$ caused adsorption efficiency decrease. The adsorption efficiency was greatly affected by $\mathrm{pH}$. For the modified membrane, the removal efficiency at different $\mathrm{pH}$ was above $75 \%$, and the adsorption was slightly affected by $\mathrm{pH}$. The maximum removal efficiency of modified mat could be achieved when the $\mathrm{pH}$ values were between 6.0 and 8.0. The possible adsorption mechanism is affinity binding between silver nanoparticles and mercury ions in addition to ion exchange between functional groups and mercury ions. The maximum adsorption occurs under nearly neutral conditions, which is favorable for real applications for natural water. 


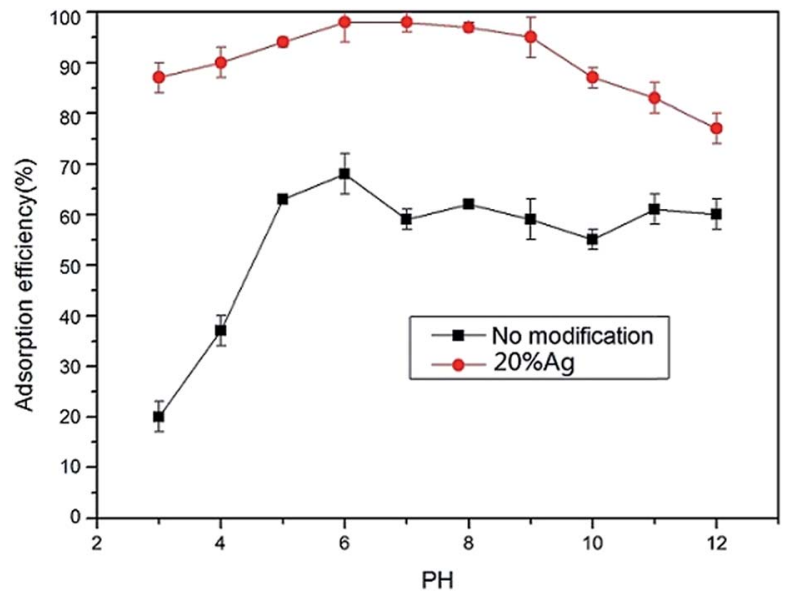

Fig. 5 Effect of $\mathrm{pH}$ on the mercury adsorption efficiency $\left(C_{0}=20 \mathrm{ng}\right.$ $\mathrm{mL}^{-1}, V=50 \mathrm{~mL}, m=50 \mathrm{mg}, 25^{\circ} \mathrm{C}$ ).

3.2.3 Effect of temperature. The effect of the temperature was explored by conducting the adsorption experiment at $30^{\circ} \mathrm{C}$, $40{ }^{\circ} \mathrm{C}, 50{ }^{\circ} \mathrm{C}, 60{ }^{\circ} \mathrm{C}, 70{ }^{\circ} \mathrm{C}$, and $80{ }^{\circ} \mathrm{C}$, respectively (Fig. S4 $\dagger$ ). The solution temperature was kept constant using a thermostatic bath. The results indicated that temperature had slight effects on the removal efficiency of the composite mat. The removal efficiency of unmodified mat showed obvious changes with temperature increasing from 30 to $80{ }^{\circ} \mathrm{C}$. As to the modified mat, high removal efficiencies (nearly 100\%) were kept at various temperatures.

3.2.4 Effect of initial mercury concentration. In order to investigate the effect of initial mercury concentration on the adsorption, the experiment was conducted by varying the concentration from 10 to $60 \mathrm{ng} \mathrm{mL}{ }^{-1}$ under the neutral conditions. The results were shown in Fig. 6a. It showed that the adsorption rate of unmodified mat decreased with concentration increasing while modified mat increased slightly. The results suggest that the unmodified mat has limited active adsorption sites for mercury, while the mat modified with AgNPs possess much more active sites including both affinity binding sites and ion exchange groups.

On the other hand, the residue concentrations according to different initial concentrations were also shown in Fig. 6b. The results reveal that the unmodified mat is not effective but the Ag-PVA composite mat shows an excellent performance, suggesting the promising applications of the composite adsorbent for mercury removal.

3.2.5 Effect of coexisting ions. In order to examine the effect of coexisting ions on adsorption and investigate the selectivity of the mat, the adsorption experiment was carried out in the presence of various coexisting ions. The results (Fig. S5 $\dagger$ ) demonstrated that most coexisting ions did not pose obvious interferences on the adsorption process of the modified mat except for high concentration of $\mathrm{Co}^{2+}, \mathrm{Cd}^{2+}, \mathrm{Cu}^{2+}$, and $\mathrm{Fe}^{3+} \cdot \mathrm{Fe}^{3+}$ showed the most serious inhibiting effect on mercury removal efficiency, which indicates that the mat is not appropriate for water treatment with high concentration of $\mathrm{Fe}^{3+}$ ions. The possible reason for the obvious inhibitation caused by the high concentration of $\mathrm{Fe}^{3+}$ was that $\mathrm{Fe}^{3+}$ could hydrolize in water solution and the $\mathrm{pH}$ of the solution sharply decreased to 2.6 when the high concentration of $\mathrm{Fe}^{3+}$ was added. As mentioned above, the adsorption efficiency was low at lower $\mathrm{pH}$, especially below 3.0. Compared with the virgin mat without modification (Fig. S5, $\dagger$ white bar), the selectivity of the composite mat to mercury ions can be obviously enhanced by the presence of AgNPs (Fig. S5, $\uparrow$ black bar).

\subsection{Regeneration and reuse}

Acid elution and thermal desorption were applied to regenerate the used mat. The used mat was immersed into $10 \%(\mathrm{v} / \mathrm{v}) \mathrm{HCl}$ or $10 \%(\mathrm{v} / \mathrm{v}) \mathrm{HNO}_{3}$ solution and shaken for 24 hours. Then the mat was reused after it was washed with distilled water to remove the remained acid. The used mat was also treated by thermal desorption. The mat was put in the oven under $150{ }^{\circ} \mathrm{C}$ for 2 hours to release the absorbed mercury. The results of regeneration and reuse were shown in Fig. S6. $\uparrow$ Thermal desorption method was more efficient than acid elution with better recovery and more recycles.

\subsection{Application to real water}

It is very critical to remove the possible elevated trace mercury in natural water bodies because of the biotransformation, biomagnification and bioaccumulation of mercury in aquatic systems. The behaviors of this composite are suitable for the
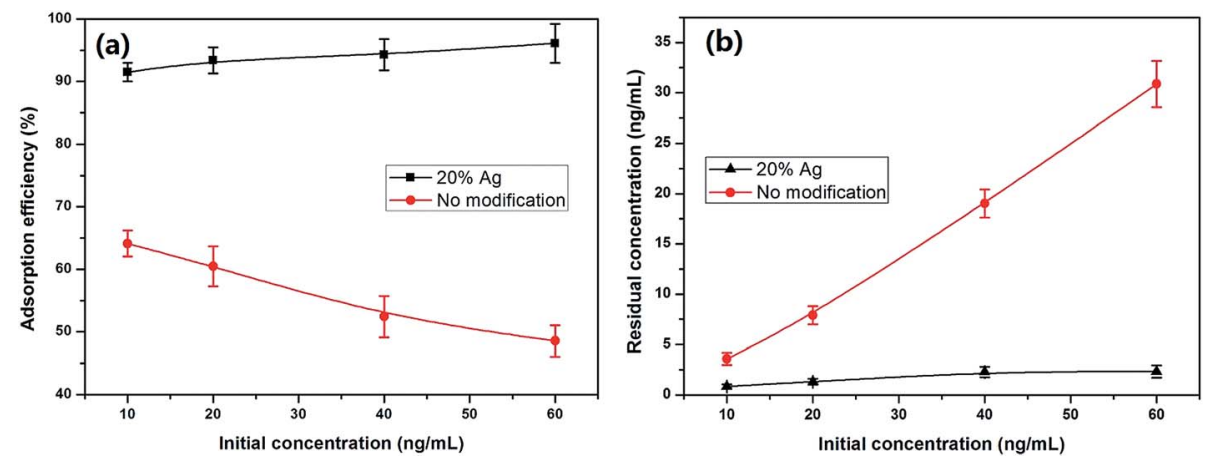

Fig. 6 Measurement of the maximum adsorption capacity and the effects of initial concentrations $\left(\mathrm{V}=50 \mathrm{~mL}, \mathrm{~m}=50 \mathrm{mg}, 25^{\circ} \mathrm{C}\right)$. 
Table 1 The real water treatment ( $n=3$, data were shown in the mean values)

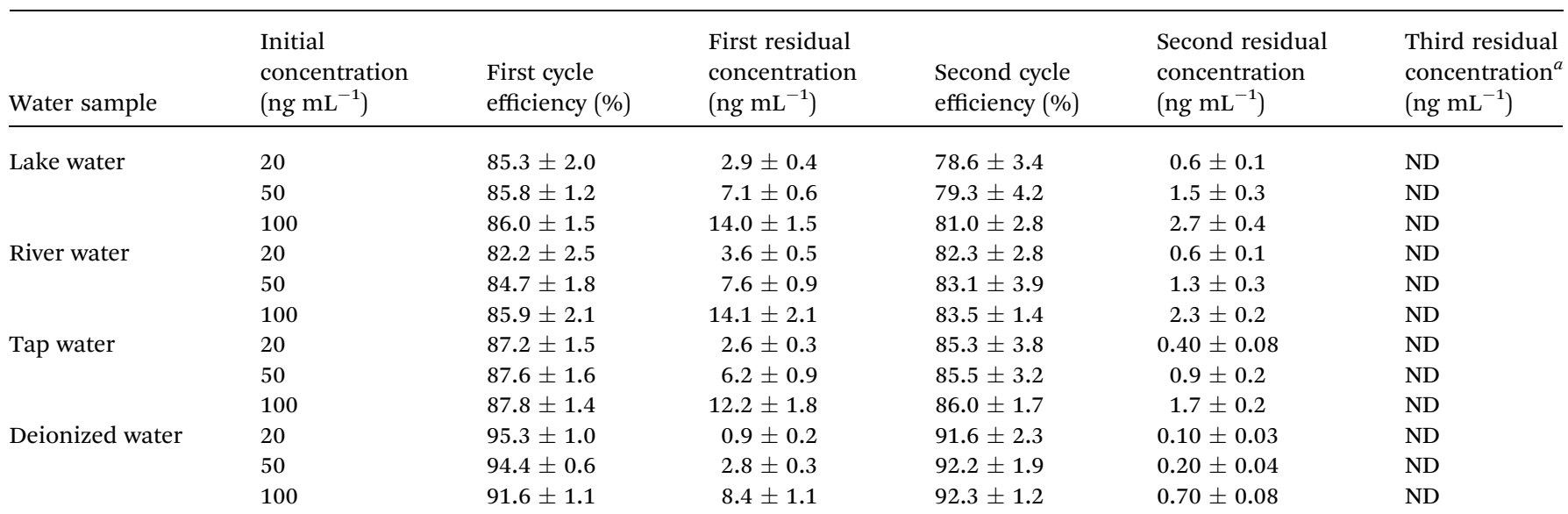

${ }^{a}$ The detection limit for $\mathrm{Hg}^{2+}$ is $0.03 \mathrm{ng} \mathrm{mL}^{-1}$.

natural water which is always with pH value 6 or 7. In order to evaluate the practical performance of the prepared mat, several real water samples (lake, river, and tap water) were collected and treated by the composite adsorbent. The simulated contamination water samples were prepared by spiking mercury solutions into the collected water samples with various final concentrations of $20 \mathrm{ng} \mathrm{mL} L^{-1}, 50 \mathrm{ng} \mathrm{mL}^{-1}$ and $100 \mathrm{ng} \mathrm{mL}^{-1}$. The results were listed in Table 1 and showed that the composite mat was feasible and effective for real water. When the water samples were treated for the third time, the concentrations of mercury in all of the water samples were below the measurement detection limit $(0.03$ $\mathrm{ng} \mathrm{mL} \mathrm{m}^{-1}$ ). Even the thermal treatment can decrease the solubility of the mat, a part of mat can also be dissolved during the real application process. The loss of the weight of the mat after use was also determined, and the mass loss of the used mat was 9.20 $\pm 0.03 \%$ compared with the original mat. The release of silver from the mat during real applications was also evaluated by the experiment. The leached silver in water samples was determined by ICPMS. The results indicated that a little bit $(6.6-8.7 \%$ of the total loaded amount of silver) of silver could be released out into water from the mat during use (Fig. S7†).

\subsection{Adsorption kinetics}

The adsorption process was analyzed using the pseudo-firstorder and pseudo-second-order equations. The pseudo-firstorder Lagergren model is generally expressed as: ${ }^{14,20}$

$$
\frac{\mathrm{d} q_{t}}{\mathrm{~d} t}=k_{t}\left(q_{\mathrm{e}}-q_{t}\right)
$$

$q_{\mathrm{e}}$ and $q_{t}\left(\mathrm{mg} \mathrm{g}^{-1}\right)$ are the adsorption capacity at equilibrium and at time $t$, respectively. $k_{1}$ is the rate constant of the pseudofirst-order adsorption $\left(\mathrm{L} \mathrm{min}^{-1}\right)$.

The above equation can be integrated as the following form:

$$
\ln \left(q_{\mathrm{e}}-q_{t}\right)=\ln q_{\mathrm{c}}-k_{1} t
$$

The values of $k_{1}$ and $q_{\mathrm{e}}$ can be determined by the slope of linear plots of $\ln \left(q_{\mathrm{e}}-q\right)$ versus $t$.

The pseudo-second-order model is generally expressed as:

$$
\frac{\mathrm{d} q_{t}}{\mathrm{~d} t}=k_{2}\left(q_{\mathrm{e}}-q_{t}\right)^{2}
$$

$k_{2}$ is the pseudo-second-order rate constant $\left(\mathrm{g} \mathrm{mg}^{-1} \mathrm{~min}^{-1}\right), q_{\mathrm{e}}$ is the amount of metal adsorbed at equilibrium $\left(\mathrm{mg} \mathrm{g}^{-1}\right)$, and $q$ is the amount of metal ions on the surface of the sorbent at any time $t\left(\mathrm{mg} \mathrm{g}^{-1}\right)$.

The above equation can be transformed into the following equation by integrating.

$$
\frac{t}{q_{t}}=\frac{1}{k_{2} q_{\mathrm{e}}^{2}}+\frac{t}{q_{\mathrm{e}}}
$$

By plotting $t / q$ versus $t, q_{\mathrm{e}}$ and $k_{2}$ can be determined from the slope and intercept.

The adsorption data at various contact time were used for the investigation of the adsorption kinetics. The linear plots of the experimental data based on both the pseudo-firstorder equation and the pseudo-second-order equation were shown in Fig. S8a and b. $\dagger$ The calculated parameters of two models were summarized in Table 2 . The results demonstrate that the adsorption process perfectly fits with the pseudosecond-order kinetic model (Fig. S8b †) indicating that chemisorptions played a key role during the adsorption process. ${ }^{50}$

\subsection{Adsorption thermodynamics}

Adsorption isotherms are mathematical models that describe the distribution of the solute species between liquid and

Table 2 Comparison of the pseudo-first-order and pseudo-secondorder parameters for $\mathrm{Hg}^{2+}$ adsorption on the meat

\begin{tabular}{llllll}
\hline \multirow{2}{*}{$\begin{array}{l}\text { Temperature } \\
\left({ }^{\circ} \mathrm{C}\right)\end{array}$} & \multicolumn{2}{l}{ Pseudo-first-order } & & \multicolumn{2}{l}{ Pseudo-second-order } \\
\cline { 2 - 3 } & $k_{1}\left(\mathrm{~L} \mathrm{~min}^{-1}\right)$ & $R^{2}$ & & $k_{2}\left(\mathrm{~g} \mathrm{mg}^{-1} \mathrm{~min}^{-1}\right)$ & $R^{2}$ \\
\hline 20 & $0.049 \pm 0.002$ & 0.8621 & & $27.31 \pm 1.62$ & 0.9998 \\
30 & $0.044 \pm 0.003$ & 0.6853 & & $33.03 \pm 2.73$ & 0.9998 \\
50 & $0.060 \pm 0.005$ & 0.8895 & & $16.85 \pm 1.12$ & 0.9999
\end{tabular}


adsorbent. To analyze its isotherm and adsorption property, experiments were conducted at different temperatures $(293 \mathrm{~K}$, $313 \mathrm{~K}$, and $333 \mathrm{~K}$ ) with $50 \mathrm{mg}$ adsorbent in $50 \mathrm{~mL}$ mercury solution. The mixture was stirred for 200 minutes to ensure reaching equilibrium. The experimental data were described using both the Langmuir and Freundlich isotherms and the parameters corresponding to the adsorption process were summarized in Table 3. It can be observed that the adsorption process fits the Langmuir isotherm better than Freundlich isotherm with higher $R^{2}$ value. From the Langmuir data it can be calculated that the maximum adsorption capacity was obtained at $333 \mathrm{~K}$ as $229.36 \mathrm{mg} \mathrm{g}^{-1}$.

Thermodynamic parameters like changes in enthalpy $(\Delta H)$, entropy $(\Delta S)$ and free energy $(\Delta G)$ were calculated according to the related parameter values derived from the modeling of

Table 3 Parameters of adsorption isotherms of the two equation models

\begin{tabular}{lcccc}
\hline & $T$ & $Q_{\mathrm{m}}\left(\mathrm{mg} \mathrm{g}^{-1}\right)$ & $K_{\mathrm{L}}$ & $R^{2}$ \\
\hline Langmuir & $293 \mathrm{~K}$ & $175 \pm 12$ & $0.430 \pm 0.023$ & 0.999 \\
& $313 \mathrm{~K}$ & $203 \pm 17$ & $0.220 \pm 0.012$ & 0.999 \\
& $333 \mathrm{~K}$ & $229 \pm 19$ & $0.140 \pm 0.008$ & 0.999 \\
\hline \multirow{2}{*}{ Freundlich } & \multicolumn{2}{c}{$n$} & $K_{\mathrm{F}}$ & $R^{2}$ \\
& $293 \mathrm{~K}$ & $2.16 \pm 0.08$ & $17.9 \pm 1.5$ & 0.913 \\
& $313 \mathrm{~K}$ & $2.18 \pm 0.09$ & $20.4 \pm 1.4$ & 0.900 \\
& $333 \mathrm{~K}$ & $2.13 \pm 0.13$ & $15.1 \pm 1.2$ & 0.900
\end{tabular}

isotherm at different temperatures $(293 \mathrm{~K}, 313 \mathrm{~K}$, and $333 \mathrm{~K}$ ) according to the (3) and (4) equation and the results were shown in Table 4.

$$
\begin{gathered}
\Delta G=-R T \ln K_{\mathrm{d}} \\
\Delta S=(\Delta H-\Delta G) / T
\end{gathered}
$$

$R$ is the universal gas constant $\left(8.314 \mathrm{~J} \mathrm{~mol}^{-1} \mathrm{~K}^{-1}\right), T$ is the absolute temperature $(\mathrm{K})$ and $K_{\mathrm{d}}\left(q_{\mathrm{e}} / C_{\mathrm{e}}\right)$ is the distribution coefficient obtained from the isotherm.

The positive value of $\Delta H$ proves the adsorption for mercury ions is an endothermic process. ${ }^{51}$ The phenomenon that $\Delta G$ increases with an increase in temperature indicates the spontaneity can increase with temperature. In addition, the negative values of $\Delta S$ reflect the slightly decreased randomness at the solid/solution interface during the adsorption.

\subsection{Antibacterial test}

Membrane fouling by bacterial pathogens is a common critical problem hampering the effective practical application of membrane/mat in water treatment. The antibacterial ability is important for the adsorbent to defend biofouling and enhance the performance in water treatment procedure. To test the antibacterial property of the mat the antimicrobial experiment was conducted and the typical results were shown in Fig. 7. AgNPs modification significantly promoted the antibacterial ability of the mat while the virgin PVA mat exhibited no antibacterial ability. Moreover, the area of the

\begin{tabular}{|c|c|c|c|c|c|c|c|}
\hline \multirow[b]{2}{*}{$C\left(\mathrm{mg} \mathrm{L}^{-1}\right)$} & \multirow[b]{2}{*}{$\Delta H\left(\mathrm{~kJ} \mathrm{~mol}^{-1}\right)$} & \multicolumn{3}{|c|}{$\Delta G\left(\mathrm{~kJ} \mathrm{~mol}^{-1}\right)$} & \multicolumn{3}{|l|}{$\Delta S\left(\mathrm{~J} \mathrm{~mol}^{-1}\right)$} \\
\hline & & $293 \mathrm{~K}$ & $313 \mathrm{~K}$ & $333 \mathrm{~K}$ & $293 \mathrm{~K}$ & $313 \mathrm{~K}$ & $333 \mathrm{~K}$ \\
\hline 600 & $2.14 \pm 0.33$ & & & & $0.30 \pm 0.04$ & $-6.00 \pm 0.43$ & $-9.80 \pm 0.57$ \\
\hline 1000 & $1.48 \pm 0.24$ & & & & $-1.90 \pm 0.16$ & $-8.10 \pm 0.77$ & $-11.80 \pm 0.89$ \\
\hline
\end{tabular}

Table 4 Parameters of the thermodynamics

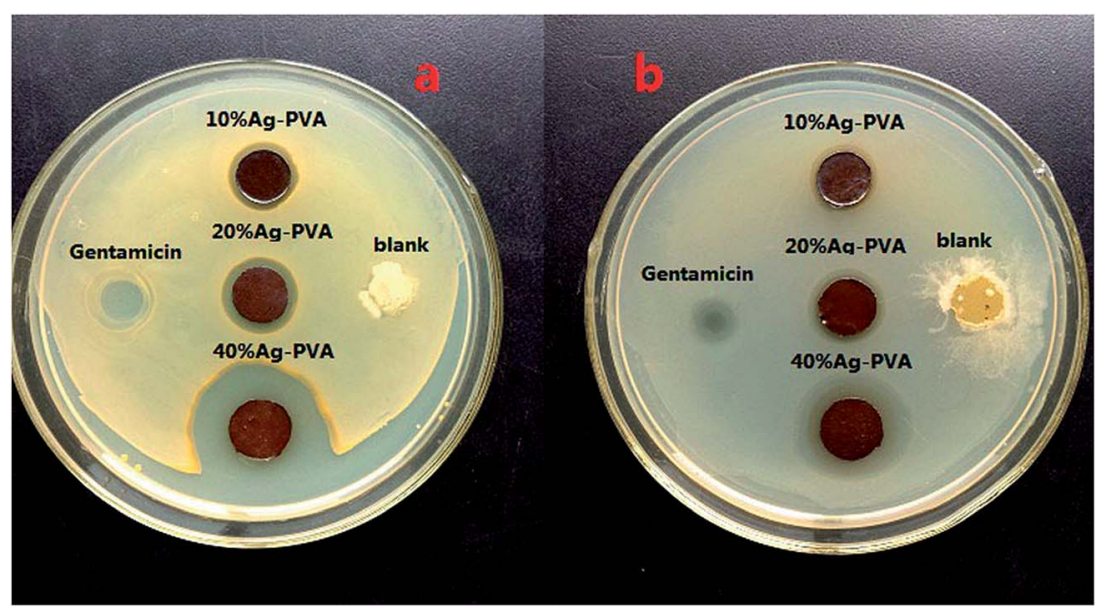

Fig. 7 The antibacterial results against (a) Staphylococcus aureus and (b) E. coli. 
inhibition zone increased with the increase of silver contents in the composite mat indicating that the silver played the key role in antibacterial activity. In general, the experimental results prove the excellent antibiofoul property of the filtration mat which is meaningful for practical utility.

\subsection{Comparison with other sorbents}

The sorption capacity of the obtained mat in this study was compared with that of the previously reported sorbents in Table S3. $\dagger$ From the results, most studies focused on powder adsorbents which suffer the disadvantage of difficult collection after use during real applications. As to the mat in our study, it is easy to collect the used adsorbent after treatment, which can minimize the risks of second pollution. Furthermore, the optimal $\mathrm{pH}$ range (6-8) in our study is relatively wider and more favorable for natural water treatment. To the best of our knowledge, most sorbents for mercury ions do not have antibacterial properties or their properties have not been evaluated. The composite mat synthesized in our study not only has good selectivity and ability for mercury sorption but also has good antibacterial property. The metal-polymer composite mat can be applied to aqueous treatment based on its multiple functional properties. The sorption capacity of the mat was satisfactory for mercury removal and comparative to other sorbents reported in literatures.

\section{Conclusions}

A Ag-PVA composite mat was successfully prepared via simple process of sol-gel and electrospinning. The composite mat showed an obvious promotion for aqueous mercury adsorption and an excellent endurance for wide $\mathrm{pH}$ value range in liquid solution. The regeneration experiment suggested that the heat treatment was an effective way to recover the mercury adsorption ability. The kinetic and thermodynamic studies showed that the adsorption process fitted well with pseudo-secondorder dynamic equation and Langmuir isotherm models. In addition, the antibacterial test proved that the mat had good antibacterial ability. The maximum adsorption capacity of the prepared mat was large and the performance was satisfactory for real applications.

\section{Acknowledgements}

This work was kindly co-funded by the National Natural Science Foundation of China (21277043), the Beijing Natural Science Foundation (8132038), and the Fundamental Research Funds for the Central Universities. The authors thank Dr Weiping Cao in Plant Protection Institute, Hebei Academy of Agricultural and Forestry Sciences for her work on antibacterial experiments. The authors also thank Prof. Jingfu Liu in Research Center for Eco-Environmental Sciences, Chinese Academy of Sciences for the determination of silver by ICPMS.

\section{References}

1 G. B. Jiang, J. B. Shi and X. B. Feng, Environ. Sci. Technol., 2006, 40(12), 3672-3678.

2 L. H. Liu, Y. Zhang, Z. J. Yun, B. He and G. B. Jiang, J. Environ. Sci., 2016, 39, 37-44.

3 J. B. Shi, L. N. Liang, C. G. Yuan, B. He and G. B. Jiang, Bull. Environ. Contam. Toxicol., 2005, 74(5), 980-987.

4 B. W. Chen, T. Wang, Y. G. Yin, B. He and G. B. Jiang, Appl. Organomet. Chem., 2007, 21(6), 462-467.

5 Y. G. Yin, Y. B. Li, C. Tai, Y. Cai and G. B. Jiang, Nat. Commun., 2014, 5(1), 4633.

6 Y. B. Li and Y. Cai, Chin. Sci. Bull., 2013, 58(2), 177-185.

7 M. Meng, B. Li, J. J. Shao, T. Wang, B. He, J. B. Shi, Z. H. Ye and G. B. Jiang, Environ. Pollut., 2014, 184, 179-186.

8 M. Meng, J. B. Shi, C. B. Liu, N. L. Zhu, J. J. Shao, B. He, Y. Cai and G. B. Jiang, RSC Adv., 2015, 5(50), 40036-40045.

9 B. Meng, X. B. Feng, G. L. Qiu, Y. Cai, D. Y. Wang, P. Li, L. H. Shang and J. Sommar, J. Agric. Food Chem., 2010, 58(8), 4951-4958.

10 G. L. Liu, Y. Cai, T. Philippi, P. Kalla, D. Scheidt, J. Richards, L. Scinto and C. Appleby, Environ. Pollut., 2008, 153(2), 257265.

11 Y. X. Mao, L. Cheng, B. J. Ma and Y. Cai, The fate of mercury in municipal wastewater treatment plants in China: significance and implications for environmental cycling, $J$. Hazard. Mater., 2016, 306, 1-7.

12 Y. M. Wang, Y. B. Li, G. L. Liu, D. Y. Wang, G. B. Jiang and Y. Cai, Elemental mercury in natural waters: occurrence and determination of particulate $\mathrm{Hg}(0)$, Environ. Sci. Technol., 2015, 49(16), 9742-9749.

13 J. G. Yu, B. Y. Yue, X. W. Wu, Q. Liu, F. P. Jiao, X. Y. Jiang and X. Q. Chen, Environ. Sci. Pollut. Res., 2016, 23, 5056-5076.

14 J. M. Choi, D. Jeong, E. Cho, B. H. Jun, S. Park, J. H. Yu, M. N. Tahir and S. Jung, J. Ind. Eng. Chem., 2016, 35, 376-382.

15 M. E. Mahmoud, A. E. H. Abdou and S. B. Ahmed, ACS Sustainable Chem. Eng., 2016, 4, 819-827.

16 K. Balasundarama and M. Sharma, RSC Adv., 2015, 5, 7386873874.

17 S. Fernandes, C. M. Eichenseer, P. Kreitmeier, J. Rewitzer, V. Zlateski, R. N. Grass, W. J. Stark and O. Reiser, RSC Adv., 2015, 5, 46430-46436.

18 M. Mon, F. Lloret, J. Ferrando-Soria, C. Mart-Gastaldo, D. Armentano and E. Pardo, Angew. Chem., Int. Ed., 2016, 55, 11167-11172.

19 S. M. Husnain, J. H. Kim, C. S. Lee, Y. Y. Chang, W. Umcd and Y. S. Chang, RSC Adv., 2016, 6, 35825-35832.

20 P. N. Diagboya, B. I. Olu-Owolabi and K. O. Adebowale, $R S C$ Adv., 2015, 5, 2536-2542.

21 S. Siva, S. Sudharsan and R. S. Kannan, $R S C A d v .$, 2015, 5, 79665-79678.

22 S. Y. Ding, M. Dong, Y. W. Wang, Y. T. Chen, H. Z. Wang, C. Y. Su and W. Wang, J. Am. Chem. Soc., 2016, 138, 30313037.

23 H. K. Moghaddam and M. Pakizeh, J. Ind. Eng. Chem., 2015, 21, 221-229. 
24 X. Wang, W. Deng, Y. Xie and C. Wang, Chem. Eng. J., 2013, 228, 232-242.

25 M. M. Rao, D. H. K. K. Reddy, P. Venkateswarlu and K. Seshaiah, J. Environ. Manage., 2009, 90, 634-643.

26 Y. S. Wang, C. C. Cheng, J. K. Chen, F. H. Ko and F. C. Chang, J. Mater. Chem. A, 2013, 1, 7745-7750.

27 M. Irfan, A. Idris and N. F. M. Khairuddin, Desalin. Water Treat., 2016, 57(43), 20388-20400.

28 G. Y. Zeng, Y. He, Y. Q. Zhan, L. Zhang, Y. Pan, C. L. Zhang and Z. X. Yu, J. Hazard. Mater., 2016, 317, 60-72.

29 Z. Karim, A. P. Mathew, V. Kokol, J. Wei and M. Grahn, RSC Adv., 2016, 6(25), 20644-20653.

30 F. E. Ahmed, B. S. Lalia and R. Hashaikeh, Desalination, 2015, 356, 15-30.

31 C. L. Zhang and S. H. Yu, Chem. Soc. Rev., 2014, 43(13), 44234448.

32 M. Aliabadi, M. Irani, J. Ismaeili, H. Piri and M. J. Parnian, Chem. Eng. J., 2013, 220, 237-243.

33 M. Teng, H. Wang, F. Li and B. Zhang, J. Colloid Interface Sci., 2011, 355, 23-28.

34 Y. Huang, D. Hu, S. Wen, M. Shen, M. Zhu and X. Shi, New J. Chem., 2014, 38, 1533-1539.

35 G. L. Wang, X. F. Xu, L. H. Cao, C. H. He, Z. J. Li and C. Zhang, RSC Adv., 2014, 4, 5867-5872.

36 G. Qi, C. Fu, G. Chen, S. Xu and W. Xu, RSC Adv., 2015, 5, 49759-49764.

37 Y. Liu, C. Tian, B. Yan, Q. Lu, Y. Xie, J. Chen, R. Gupta, Z. Xu, S. M. Kuznicki, Q. Liu and H. Zeng, RSC Adv., 2015, 5, 1563415640 .
38 E. Sumesh, M. S. Bootharaju and A. T. Pradeep, J. Hazard. Mater., 2011, 189, 450-457.

39 L. Tian, P. Wang, Z. Zhao and J. Ji, Appl. Biochem. Biotechnol., 2013, 171, 1890-1899.

40 N. Ma, Y. Zhang, X. Quan, X. Fan and H. Zhao, Water Res., 2010, 44, 6104-6114.

41 A. A. Taha, J. Qiao, F. Li and B. Zhang, J. Environ. Sci., 2012, 24, 610-616.

42 M. H. Tai, P. Gao, B. Y. L. Tan, D. D. Sun and J. O. Leckie, ACS Appl. Mater. Interfaces, 2014, 6, 9393-9401.

43 M. Liu, L. Song, Y. Wang, Z. Cheng and J. Li, High Perform. Polym., 2014, 26, 483-487.

44 H. Liu, J. Bai, S. Wang, C. Li, L. Guo, H. Liang, T. Xu, W. Sun and H. Li, Colloids Surf., A, 2014, 448, 154-159.

45 J. Y. Chun, H. K. Kang, L. Jeong, Y. O. Kang, J. E. Oh, I. S. Yeo, S. Y. Jung, W. H. Park and B. M. Min, Colloids Surf., B, 2010, 78, 334-342.

46 Y. Meng, Nanomaterials, 2015, 5, 1124-1135.

47 S. Deng, H. Liu, W. Zhou, J. Huang and G. Yu, J. Hazard. Mater., 2011, 186, 1360-1366.

48 Y. Xu, Z. Qin and X. Liu, J. Hazard. Mater., 2015, 283, 252259.

49 E. Sumesh, M. S. Bootharaju and A. T. Pradeep, J. Hazard. Mater., 2011, 189, 450-457.

50 G. Li, B. Shen and F. Lu, Chem. Eng. J., 2015, 273, 446-454.

51 S. X. Li, F. Y. Zheng, Y. Huang and J. C. Ni, J. Hazard. Mater., 2011, 186, 423-429. 